ance in the solution of problems by computers and the design and construction of the computer (SWAC) at the Bureau's Institute of Numerical Analysis at Los Angeles. Circular No. 551 of the National Bureau of Standards (pp. 146. Washington, D.C. : Government Printing Office, 1955; 2 dollars) is a bound book in which the more important engineering aspects of the Bureau's electronic computer programme are presented. It is based largely on the experience gained in relation to SEAC (National Bureau of Standards eastern automatic computer) and DYSEAC (second SEAC). The contents of the circular consist of eight articles, in addition to an introduction by S. N. Alexander, who gives a brief résumé of the historical development of the programme. The topics discussed in the articles include dynamic circuitry techniques, design of systerns, high-speed memory development, input-output devices, construction and maintenance, in addition to a review of three years of operational experience on SEAC.

Both SEAC and DYSEAC are high-speed, automatically sequenced, electronic digital computers, in which extensive use is made of germanium diodes for switching and gating. They have mercury delay-line internal memories, and SEAC has an additional electrostatic memory. Since September 1950, SEAC has been in almost continuous daily use, but interspersed with its productive computational operation there have been periods during which research and development have been conducted on it. The new constructional techniques that have resulted from the experience with this computer have been incorporated into DYSEAC, and this latter represents a considerable advance in the computer art, though it was designed to serve as an experimental nucleus for more complex data-processing networks.

\section{The Shape of the Earth}

THE different methods for determining the Earth's ellipticity $c$ are discussed by G. Tiercy in No. 50, Series $A$, of "Publications de l'Observatoire de Genève" (Fasc. 1 of Vol. 6). The four main methods are : the geodesic method by measuring the length of $1^{\circ}$ of the are of a meridian; the determination of gravity at various latitudes; the precessional method ; and the perturbations observed in the motion of the Moon. While the geodesic value $1 / 297$, adopted in 1911 by the International Conference of Astronomical Ephemerides, is adhered to, nevertheless there exists some uncertainty regarding its accuracy, for the value of $1 / 294$, obtained from the results of the lunar dynamics, still presents a difficulty in accepting a unique and definitive value of $c$. Reference is made to Bulletin No. 78 of the United States National Research Council, published in 1931, which contains a memoir by W. D. Lambert, who expressed the opinion that the dynamic solution could be made to approximate to the geodesic solution if one or the other of three possibilities was accepted: changes in the values of the secular variations deduced from observations; changes in the data for the Earth's figure; and contingent corrections in the very complex mathematical theory of the problem. Tiercy then proceeds to consider another possibility, which may be briefly summarized as follows. In 1932 Wavre dealt with the problem of the oblateness of the Earth, retaining terms of the order of $\omega^{4}, \omega$ being the angular velocity, and obtained for the terrestrial meridian a slightly flattened curve with reference to an ellipse with the same poles and the same equatorial radius. The theoretical value of the flattening obtained by Wavre was $c=(a-b) / a \fallingdotseq 1 / 295$, and the small portion $\Delta$ intercepted by the radius between the two curves is derived from $\Delta=k b \omega^{4} \sin ^{2} \varphi^{\prime}$, where $k$ is a constant and $\varphi^{\prime}$ the geocentric latitude. From this it was found that $\Delta=310$ metres. With the aid of two diagrams, Tiercy shows that Wavre's investigations practically eliminate the discrepancy which was obtained for $c$, by the following com. promise. Taking the surface of the Earth to conform to the international ellipsoid ( $c=1 / 297$ ) but flattened in accordance with the formula given above, the flattened globe would behave very closely, from the point of view of lunar dynamics, as an ellipsoid in which $c=1 / 295$. Admitting that it is only a compromise, it is suggested that it can last until a more ingenious interpretation will produce reconciliation of the different results.

\section{Year Book for 1955 of the Library Association}

A Feature of the Year Book, 1955, of the Library Association (pp. 193 ; from the Association, London; 21s.; 15s. to members) continues to be the usual graded list of text-books and works of reference, which has a value far from confined to those preparing for the examinations of the Association, the regulations and syllabus for which are also given. The entries under science and technology are well chosen and balanced, and the scientific worker himself might well turn to these lists for references to books on general science, including the history of science, natural history and biological sciences. For the science teacher they should be particularly useful.

\section{American Association for the Advancement of Science : Meeting in Atlanta}

Tex 122nd meeting of the American Association for the Advancement of Science will be held in Atlanta, Georgia, during December 26-31. Sixteen sections of the Association and approximately sixty. five affiliated and associated societies will meet concurrently in Atlanta. The programme includes a joint meeting of the Assoriation with the Oak Ridge Institute of Nuclear Studies, at which twenty-two papers on "Atomic Energy and Agriculture" will be given, and three symposia on, respectively, the new psychiatric drugs, the treatment of alcoholism, and recent concepts in clinical chemistry. Dr. James $R$. Killian, jun., president of the Massachusetts Institute of Technology, will give the Sigma Xi Lecture, and Mr. Newman Bumsted, assistant chief of cartographic staff, the National Geographic Society Lecture, his subject being "Atlantic's Farthest Shores". Further information about the meeting can be obtained from the Director of Public Information of the Association, Dr. Sidney S. Negus, Medical College of Virginia, Richmond, Virginia.

\section{Soviet Science To-day: Symposium in London}

A SYMPosrum on "Soviet Science To-day", arranged by the Society for Cultural Relations with the U.S.S.R., will be held on November 29 at 7 p.m. in the Caxton Hall, Victoria Street, London, S.W.I. The symposium will take the form of a question-andanswer meeting, and questions should be submitted in advance. Three aspects of current developments in the U.S.S.R. will be considered by the following : Academician N. V. T'sitsin, director of the Permanent Agricultural Exhibition, Moscow (on agriculture); Prof. C. F. Powell, professor of physics in the University of Bristol (on atomic energy); and Dr. S. Lilley, of the Department of Extra-Mural Studies, 